\title{
Analyzing Impact of a Crisis on Bank Financial Ratios
}

\author{
Osman $\mathrm{Nal}^{1} \&$ Andrew Cai ${ }^{2}$ \\ ${ }^{1}$ Assistant Professor of Finance, School of Business and Leadership, Our Lady of the Lake University, San Antonio, \\ TX 78207, USA \\ ${ }^{2}$ Student, Clements High School, Sugar Land, TX 77479, USA \\ Correspondence: Osman Nal, School of Business and Leadership, Our Lady of the Lake University, San Antonio, \\ TX 78207.
}

Received: October 6, 2020

Accepted: November 7, 2020

Online Published: November 13, 2020

doi:10.5430/afr.v9n4p17

URL: https://doi.org/10.5430/afr.v9n4p17

\begin{abstract}
In this study we provide a practical framework and methodology for analyzing the effects of banking shocks (economic or financial in nature) on bank fundamentals, that avoids the use of complicated econometrics methods. For this, we focus our attention to the effects of the 2007-2008 global financial crisis on the four largest US banks and examine the variation of trends in the select financial ratios for those institutions using quarterly regulatory data running from 2002-Q4 to 2020-Q2. We start by plotting time series charts of those financial ratios for each bank and compare the before-crisis, transition and after-crisis periods. For this, we simply fit trend lines with three parameters of shift, slope, and volatility to the banking data. The shift parameter describes the level change of the variable when before- and after-crisis periods are compared. The slope parameter pronounces the difference in steepness of the trend lines, while the volatility parameter is associated with all three periods and describe the variation in the data during each period. Our results indicate that capital ratios, an important regulatory financial ratio, are higher across the board in the after-crisis period compared to before-crisis period, suggesting a positive shift. We don't see significant changes in slope parameter for the capital ratio series leading us to suggest the use of dummy variable regression model where slope is treated as a fixed constant. We further show that pre-crisis and transition periods are characterized by higher volatilities that ultimately subside in the after-crisis period. Lastly, we conclude by suggesting that financial practitioners use the shift, slope and volatility parameters in understanding trends in financial time series data since it is easy to implement and interpret the results compared to more sophisticated econometric models.
\end{abstract}

Keywords: financial crisis, banking shocks, financial ratios, trends

\section{Introduction}

Motivation for this paper comes from the desire to comprehend the effects of the 2007-2008 global financial crisis on the financial ratios of large US commercial banks from a financial practitioner's point of view. We want to find a simple, and yet effective way, to understand the effects of banking shocks, such as financial crises, on bank fundamentals. This is important and should be addressed because it is ultimately the financial practitioners that make the financial decisions such as capital budgeting, working capital managements and portfolio optimization decisions that ultimately leads to those financial disruptions. For example, mispricing of financial risks is considered as one of such failures of financial professionals.

We focus our attention on commonly used financial ratios for banking and try to make sense of the changes in trends following a "shock" regardless of it being caused by economic, financial, or any other events. Our method in a nutshell employs the following steps: (i) Select bank financial ratios of interest and calculate quarterly values for those ratios, (ii) plot a scatterplot chart for each bank financial ratio over time, (iii) fit an appropriate model and corresponding trendlines consistent with the data and quantify the effects of the shock event (i.e. financial crisis) using shift, slope and volatility parameters. We claim that this approach has appealing features for practitioners in understanding how banks are affected by financial crises and banking shocks.

Our objective as such is to provide a simple framework that would help practitioners to understand the effects of what we call as shocks on the financial ratios of commercial banks. For that, we divide the time series data of the financial variables of interest (i.e. financial ratios) into three periods: the before-shock, transition period, and after-shock periods. These periods are also easy to identify when the progression of events is traced historically. It is 
common belief that crises periods are preceded by a volatile environment, and that when crises begin, banks try to re-position themselves to preserve their financial ratios. The transition period usually ends with new government regulatory policies taking effect. For example, the transition period following the 2007-2008 financial crisis ended with the implementation of the Dodd-Frank Act of 2010.

When we investigate the effects of a shock, like a financial crisis, in bank fundamentals such as demand deposits, interest rates offered, trading book, for example, it is reasonable to focus attention on financial ratios for sake of consistency. As there are large banks and smaller ones with varying sizes, this provides standardization and makes banks comparable to each other by controlling for parameters such as asset size and geographical location. To elaborate on this point, consider the example of the implicit interest rate charged (resp., paid) measured by dividing interest income (resp., expense) by total deposits. Why to use such a fraction rather than simply looking into interest income/expense, i.e. the variable on the numerator? Since banks' deposits are not fixed, and varies over time, it is reasonable to check the mentioned ratio instead, which is standardized, and further, this enables us to compare banks amongst themselves as well as compare a given bank across time.

The standard forecasting technique in academic financial literature is to utilize time series models in integrating the progression of a variable over time to extrapolate the given data to make predictions of the future. Univariate time series models of the 1980s have proven to be more successful in forecasting financial variables than simultaneous-equations models of the 1960s according to Greene (2017). However, those methods are in general overly complicated for practitioners, and accessible only to a narrow group of academicians. We propose a method that has appealing features such as simplicity in implementation and interpreting by practitioners. More specifically, we introduce the three parameters of shift, slope and volatility associated with financial ratios of interest for individual commercial banks to analyze the changes in the trendlines when compared before and after the shock.

Two research questions that will be addressed in this study are as follows. Firstly, "what methodology is available for financial professionals to assess the effects of banking/financial shocks?" Secondly, "how can we extract patterns from financial time series data without going into too much technicality, and without losing sight of the big picture?" The rest of the paper is organized as follows. The next section, that is, Section 2, is a brief literature review. Section 3 explains how financial ratios can be analyzed over time by way of trendlines and the three parameters using data for the largest four financial institutions in the US. In addition, it introduces the general framework and model choice. Section 4 contains a discussion of the findings. Section 5 concludes the paper and presents future research suggestions.

\section{Literature Review}

There is an enormous body of literature on banking and financial crises. The financial crisis of 2007-08 has certainly increased interest as it affected the livelihood of consumers. The 2011 report of the financial crisis inquiry commission of the US Congress, titled The Financial Crisis Inquiry Report: Final Report of the National Commission on the Causes of the Financial and Economic Crisis in the United States (2011), provide an excellent summary of the financial crisis and its likely causes. The report, rather than pointing to a single cause, focused attention on an array of financial players including regulators and policymakers that was at fault prior to the financial crisis.

The literature starting with Diamond and Dybvig (1983) design banking institutions in a microeconomic model and explain bank runs with fundamental properties of banks such as the fractional deposit system. They show how banks subject to bank runs can attract deposits and how deposit insurance can provide superior contracts to those offered through the market. Freixas and Rochet (2008) provide a survey of the subsequent microeconomics literature of banking. Some of the subjects covered there include the role of financial intermediaries, lender-borrower relationship, systemic risk, and industrial organization approach to banking. The key component in almost all the models surveyed seem to be the design of financial agents, namely banks, firms and depositors, as players, and then constructing payoff matrices with asymmetric information that can be solved using the tools of game theory.

Maniam and Nal (2012) suggest that too-big-to-fail banks will be bailed out by policymakers if they deem these institutions will pose risk to the overall economy. One might object to that claim as regulators did not rescue the fledgling investment bank Bear Stearns in March of 2008, which led to the ultimate failure of that bank as a result of its exposure to risky asset-backed securities. It would be fair to say that regulators' primary fear would be a bank run on the whole financial system caused by a weak link in the chain. Most of regulation is to devise early warning systems to identify those weak links and fix them if possible.

Bernanke (2018) provides a nice summary of the real effects of a financial crisis when credit gets disrupted by 
collecting evidence from the global financial crisis. Economists failing to predict the crisis ahead of time is a concern obviously, however an even more problematic issue is that they seem to underestimate its consequences for the broader economy, and that is the main contribution of that paper. Studies comparing financial variables before and after a financial/banking event are also abundant. For example, Bulut and Nal (2009) analyze the effectiveness of market disciplinary forces in the before and after of the 2001 Turkish banking crisis. They estimate and report results from a 2-Stage and 3-stage least squares instrumental variable regression. This current paper, instead, ignores technical details and focus attention on the methodology that can be employed in identifying change.

All these studies are highly technical in general and not readily available to the general public as it requires significant understanding of advanced time series modeling. Hence the concern of our paper, to make the analysis easier to grasp by using simple visual tools such as the ones we propose, i.e. shift, slope and volatility. In that sense the study that is most similar to our paper is that by Litterman and Sheinkman (1991), where they study the shape of a yield curve over time. They construct a yield curve factor model and explain yield curve movements by describing it with a combination of three independent movements, namely, level, steepness, and curvature. They also provide a practical formula in their paper that enable them to quantify those three parameters that they introduce.

Lastly, we would like to point out a large body of literature of quantitative risk management models that uses econometric methods. In banking the preferred risk measure among practitioners since the middle of 1990's has been the Value-at-Risk (VaR) metric. Embrechts et al. (1999) provide a nice survey of risk management techniques utilized in insurance and banking and why there had been a need for better and stronger risk measures. In particular, they point out to large losses in those industries which don't fit the model that has been used previously. They also caution the reader that the VaR measure has its own flows. For example, it is not a coherent risk measure.

Traditionally market returns have been modelled with normal distribution that has thin tails. However, a growing body of empirical evidence suggests that other distribution functions should be used to model heavy-tails. For example, Guo (2017) discusses four heavy-tailed distributions using the data set from the S\&P 500. Their results indicate that the skewed $t$ distribution has superior empirical performance compared to the student's $t$ distribution. These types of studies are quite technical for the practitioners. In this paper, we will rather focus on trend analyses instead, where we would like to pursue a more qualitative approach.

\section{Analysis}

It's been more than a decade since the global financial crisis wreak havoc on US financial markets. The crisis that began in the housing market quickly spread to other parts of the financial markets via securitization. Financially engineered, complex financial securities such as collateralized debt obligations (CDOs) made it very difficult for financial institution managers and government regulators to price risks properly. Banks in the US and elsewhere found themselves in the middle of mayhem, and a large number of US banks (i.e. 491 banks between Jan. 1, 2008 and Dec. 31, 2012) failed during and in the aftermath of the crisis. This is in stark contrast to only five bank failures in the preceding five years. It is customary to look into wellbeing of financial institutions by comparing financial ratios (see, for example, chapter 4 in Keown, Martin, and Petty (2014) for a somewhat detailed treatment) as we do next.

\subsection{Charts of Quarterly Financial Ratios}

Figure 1 below provides our main motivation for this paper. In the figure, we have the total capital ratio for the four largest US banks. Capital ratio in its simplest sense is defined as the sum of Tier 1 and Tier 2 capital divided by total assets for a given financial institution. It measures how well a bank is capitalized, and as such shows the riskiness of a bank. Since capital serves as a buffer against unexpected losses on the asset side of the balance sheet, more capital is associated with a safer banking business. Now the downside of it is that the more a bank raises capital its return on equity is smaller, i.e. investors earn a lower rate of return as the company gets deleveraged as capital rises. Hence, there is this tension within the firm to find the right balance of risk and return. Yet another player is also part of the picture and that is the government regulators which impose minimum capital requirements. Any bank which have below threshold capital, as a result, pays some sort of insurance fee to the FDIC since it is deemed "risky".

Now given this background, when we look at Figure 1 we observe that bank capital ratio has been somewhat stable in all four banks at a rate ranging between 11 percent (Bank of America) and 13 percent (Citibank). It seems clear from the chart that rates started rising from 2009-Q1 and somewhat fluctuating as well, all the way to 2015-Q2 when it is stabilized again. What is interesting is that now capital ratio is at a new plateau which is of a higher level than its previous level, ranging between 13 percent (Bank of America) and 15 percent (Citibank). I am somewhat ignoring the last two quarters as we are in the middle of a big recession as of now due induced by a public health crisis. 
Figure 1 provides insight into examining time series financial data. We can split the time span into three periods: the time before 2008, years between 2009 and 2012, and the time after 2013. Those periods are roughly associated with before crisis, during crisis, and after crisis events. We recognize that there is a time lag between the real shocks and how business decisions within a bank respond to those changes within two or three quarters.

We will next investigate whether the same phenomena hold for different financial ratios as well. If it does, that would mean that we have a pattern and that we can construct, though simple, a practical method for analyzing financial and economic shocks, and their effects on financial ratios. We next present charts for various performance financial ratios for the largest four financial institutions in the US: JPMorgan Chase, Bank of America, Citibank and Wells Fargo bank. These banks are large financial institutions with over 1 trillion dollars in assets under management. We compare these banks across time and see how their financial ratios changed before, during and after the 2007-08 financial crisis. The key ratios of interest for which we will look at change before and after the 2007-08 financial crisis include (i) capitalization ratios, (ii) liquidity ratios, (iii) earnings and profitability ratios, (iv) margin analysis ratios, and (v) loan analysis. Financial ratios related to these characteristics are very useful in understanding the healthiness of a financial institution.

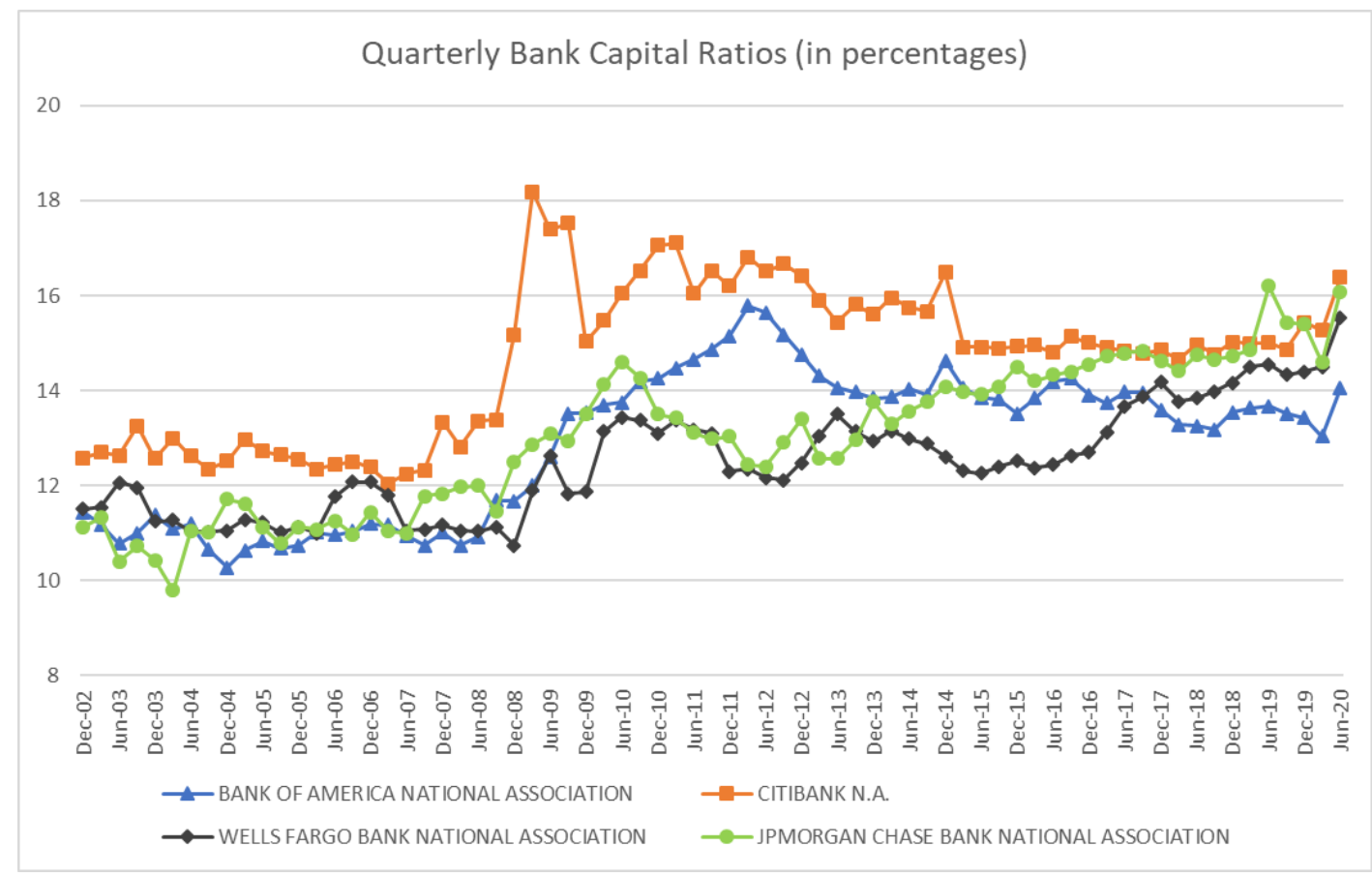

Figure 1. Total capital ratio at the four largest US banks (2002-2020)

The time span for which we have consistent and high-quality data is the period from quarter 4 of 2002 till second quarter of 2020. We will roughly break that time span into 3 periods. Pre-crisis period runs from beginning of $4^{\text {th }}$ quarter of 2002 until the end of second quarter of 2007. Crisis period runs from third quarter of 2007 until second quarter of 2010 (a 3-year period), and lastly from 2010/Q3 until 2020/Q2. We would like to point out that the data exhibits some signs of distortion in the 2020/Q1 and 2020/Q2 periods, most likely as a result of the pandemic that is expected to contract US economy by about 6 percent.

We now introduce the shift, slope, and volatility parameters that will enable us to describe the trendlines inherent in the time series financial ratios. We use the shift parameter to describe the shift in the trend line fitting the financial time series data as we move from one period to the next. The slope parameter on the other hand will be used to describe the change in the slopes of trendlines as we move from one period to the next. Lastly, we utilize the volatility parameter to describe the variation in each of the three periods and compare them with each other.

Each US financial institution provide call reports to its regulators on a periodic (quarterly) basis. These banks are assigned a unique ID RSSD number by its regulator, that is, the Fed, FDIC, or OCC. It turns out that, following the adoption of the Dodd-Frank Act, call reports of US banks have become available on the Federal Financial Institutions Examination Council (FFIEC) website (https://www.ffiec.gov/) spanning from fourth quarter of 2002 to the present day. For our research we ended the data set at the second quarter of 2020. 
In general, the quarterly call reports that each bank files with its regulator contains regulatory data, for example, bank balance sheets, income statements, and cash flow statements. While reports prior to 2002 are also available elsewhere, we did not utilize them for at least two reasons: (i) the methodology for data before 2002 is different and as a result creates consistency concerns, and (ii) they were not necessary to examine effects of the 2007-2008 financial crisis.

Through the FFIEC database call reports can either be downloaded for individual banks or for all functioning banks in a given quarter, with the latter known as bulk form data. For this study, we downloaded bulk data ranging from the first call reports, on 12/31/2002, to the last call reports available, on 6/30/2020. These bulk data files contained raw data regarding specific variables, which were organized for simple processing. In Figure 1 you can see the capital ratio at the four largest banks. Capital ratio levels were low, at approximately 11 percent before the crisis. Following the crisis, and especially after 2010, capital levels seems to have remained high at around 14 percent flat.

We next inquire about Figure 2, which depicts the liquidity ratio at the four largest US banks proxied by net non-core funding dependence, i.e. the sum of total time deposits of more than $\$ 100,000$ before March 2010 and more than $\$ 250,000$ after that date. Obviously, these numbers represent the deposit insurance limits in the US. As a result, deposits below those thresholds are treated loyal while those time deposit accounts above those limits are at risk to be lost at short notice.

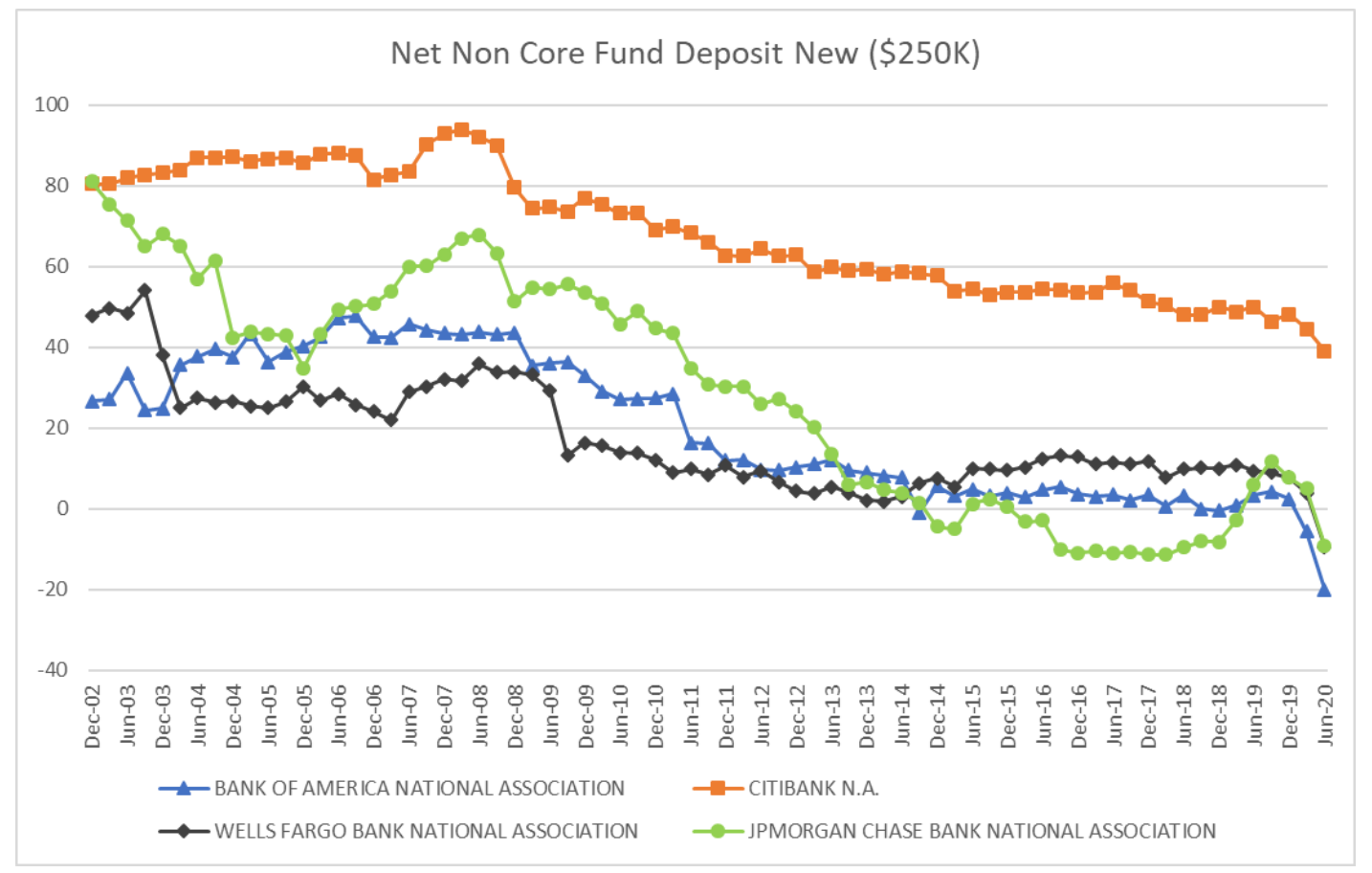

Figure 2. Ratio of net non-core deposits above $\$ 250,000$ to total deposits at the four largest US banks between 2002-Q4 and 2020-Q2. This is can be considered as a liquidity ratio

We also observe that, in Figure 2 all four graphs are downward slopping suggesting banks are trying to expand the depositor base and gather more loyal deposits that will be under deposit insurance guarantee. Deposits in excess of $\$ 250,000$ seem to be reducing. That can have multiple explanations. One is that because banks are no longer as profitable as they were pre-crisis, risky investors with large deposits above $\$ 250,000$ find new ports to park their moneys. Alternatively, it might be the very belief that banks are exposed to higher levels of risk compared to their historical levels that might have caused depositors to move out. Another explanation would be that banks learned their lesson and they implemented targeted strategies to attract these new deposit types.

We will next investigate profitability ratios measured in terms of net income as a percentage of total assets. These ratios presented in Figure 3 are significant in terms of analyzing how the banking business is performing overall as the goal in those banks is to maximize profits. One can easily observe that profit ratios were relatively higher before the crisis, ratios dropped during the crisis, and has since picked up back to pre-crisis levels. It seems that, among the three parameters, it is not slope or level parameters that has the potential to explain the response of profitability ratios to shocks but it is rather volatility. Yet before we can make a definitive conclusion, we would need to test the model 
to see if it really fits the data. In the next section, we provide an example for how to test these hypotheses within the framework of regression analysis.

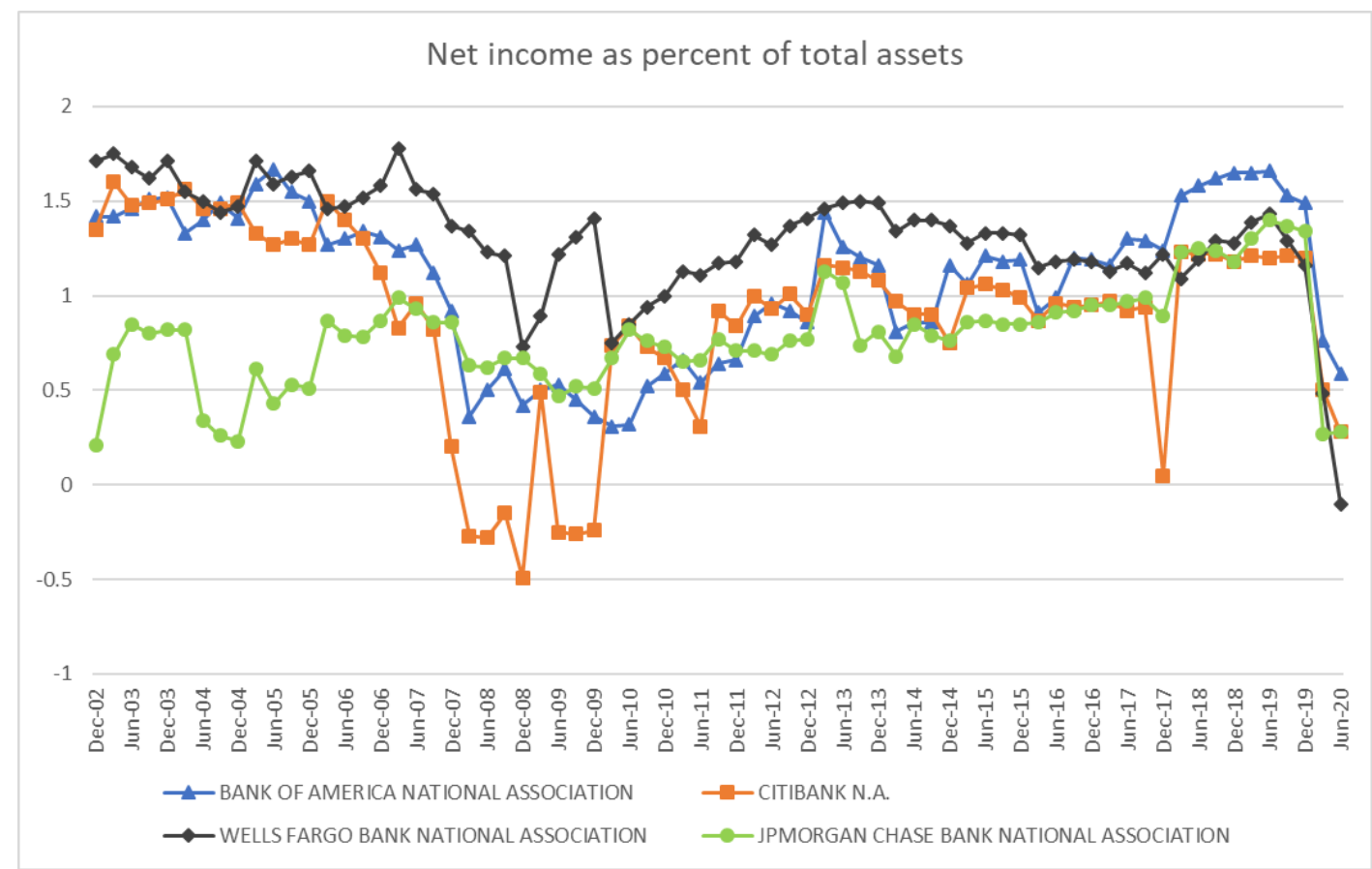

Figure 3. Profitability at the four largest US banks measured as the net income divided by total assets

Figure 4 relates to the so-called "margin analysis". From a historical perspective, the traditional banking business has been to accept deposits from individuals and extend loans to companies. The key idea along the way is that banks are able to earn a higher interest rate than they pay thanks to the upward sloping yield curve. This is referred to as maturity intermediation. It is a risky business if all depositors request their funds at the same time since banks only keep a fraction of the deposits at any given time as reserves with the Federal Reserve System.

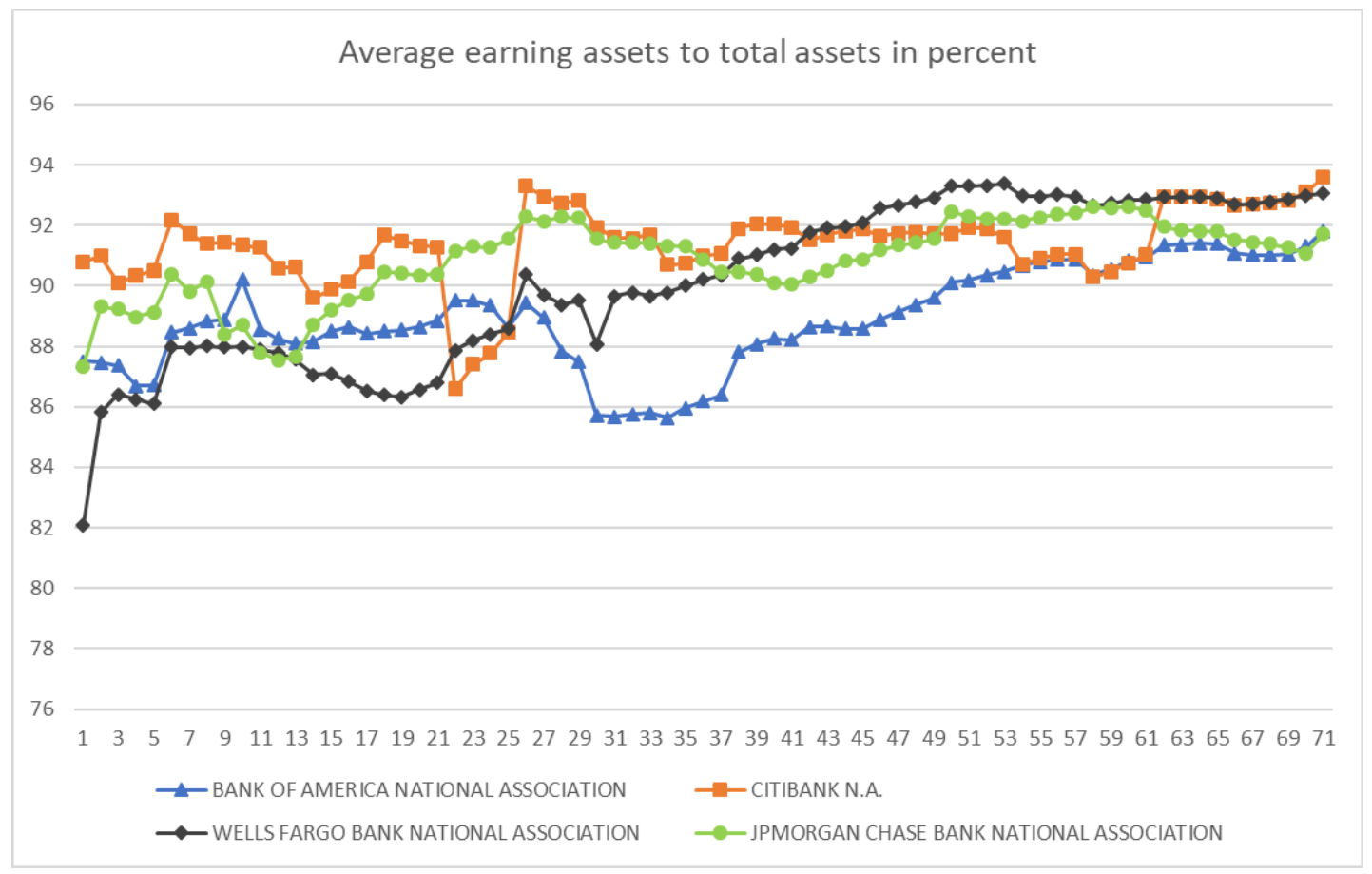

Figure 4. Ratio of average earning assets to total assets at the four largest US banks 
If banks can keep those margin ratios high, they will continue making money. Historical trends are changing, and as other companies and funds offer services similar to banking services bank margins have eroded over the years. Banks have been creative in finding new return generating ventures one of which is fees and commissions for various services provided. The proxy we use in Figure 4 is average earning assets to total assets. The more assets are allocated to their most productive uses, banks will keep generating profits. It seems from the shape of the curves that those ratios have been quite fluctuating before 2010. Since then, the ratios are steadily increasing. So, one might characterize volatility for margin ratios before 2010 and slope afterwards.

Lastly, we analyze Figure 5, which is related to loan and lease analysis. As mentioned above, banks are in the business of extending long term business loans. There is always credit risk that some of those loans will not perform and creditors will simply default. Thankfully during good economic times, that ratio is not too high, and banks are profitable in the sense that even though there are some loans which will have to be written off, the loans that pay back interest more than offset those losses.

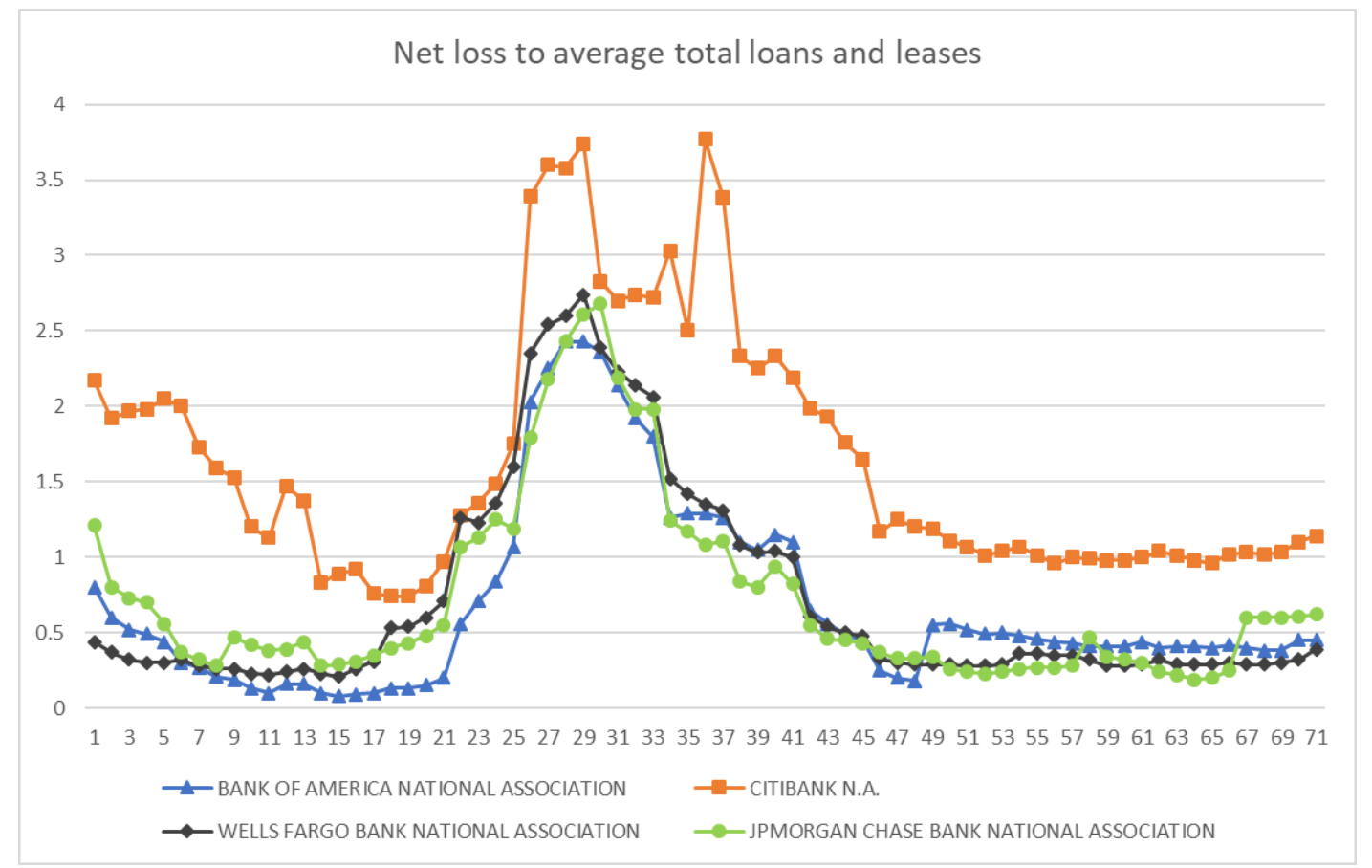

Figure 5. The ratio of net loss to total loans and leases at the four largest US banks from 2002-Q4 to 2020-Q2. This ratio is one of the few financial ratios intended to analyze the asset side of bank balance sheet

We notice, in Figure 5 that losses have been low before the crisis, raised significantly during a two or three years of crisis period, and went back to normal pre-crisis periods since. In that sense, we can characterize loan analysis as "level" before the crisis, "volatility" during the crisis, and back to "level" parameter after the crisis. Looking into all five of these figures enabled us to get some insight into how to analyze effects of a change in qualitative terms. It seems that in general the crisis period in the middle is associated with volatility and pre-crisis and post-crisis are characterized by shifts and changes in slopes.

Clearly, pre-crisis period is characterized by high volatility in all financial ratios. Later in the paper we utilize standard error to numerically proxy volatility of bank financial ratios. High volatility is associated with and could be interpreted to have happened as a consequence of increased risks before the financial crisis. The post-crisis is less volatile for almost all financial ratios. One interpretation would be that, in part, some lessons are learned by banks during the crisis and immediately after the crisis. There is certainly a shift effect for capital and profitability ratios while slope is prevalent for the remaining ratios including liquidity, margin and loan ratios. Hence these select ratios provide us with great insight on how to use the three parameters to describe the change in trend lines following a banking shock.

\subsection{Building a Framework}

For purposes of the analysis, a clear challenge that practitioners face is to quantify these changes in level, slope, and volatility parameters that we motivated in the previous section. That would enable better understanding and 
forecasting of these financial ratios in the face of future shocks and crises. For this purpose, we propose a two-step process. First one of these processes would require the proper extraction and storage of appropriate financial data and calculation of relevant financial ratios. Second step would be to fit a good model to the data, and then interpret the three parameters based on that model. For example, if the chart exhibits a shift in the financial ratio of interest, one would be inclined to use a dummy variable regression analysis. Alternatively, quantifying pre-crisis period would require some measure of volatility that needs to be developed. We propose one in the relevant subsection below. In what follows next, we elaborate on these points somewhat briefly, leaving details to future research.

\subsubsection{Calculating Financial Ratios}

The charts in the previous section were calculated based on data available in the call reports of the four largest US financial institutions, i.e. commercial banks. Bank call reports in the US are quarterly and banks are required to submit this regulatory data to its government regulator such as the Federal Reserve, OCC or FDIC. Each variable in the financial statements is assigned an 8-character-long symbol, such as RCON2200, which is standardized as four letters followed by four numbers. These reports have sections which are very easy to read and follow. For example, the report would generally start with balance sheet and income statements followed by various capital ratios and other financial ratios.

Uniform Bank Performance Reports (UBPR) is an alternative analytical tool available to regulators and researchers. All call report data is already classified and made available at a simpler form in UBPR reports. UBPR reports have their own mnemonic 8-letter formulas similar to call reports. Thus, we use UBPR reports in this paper and here are the variables that we use. "Capital ratio" is the most easily visible ratio. It is directly reported in both call reports and UBPR reports. The mnemonic is UBPRD488. Notice that there are variations of this ratio. For example, the Tier-1 capital ratio (UBPRD486) has a similar purpose, and we are not using it in our analysis.

For the liquidity ratio we use "Net Non-Core Funding Dependence", for which the code is UBPRK447. It is calculated as the ratio of "Noncore liabilities less short-term investments (UBPRK445-UBPRE582)" to "Net Loans and Lease Financing Receivables, Investment Securities and All Other Real Estate Owned (UBPRD584)". For the profitability ratio, we use "Net Income as a percent of Average Assets", for which the UBPR code is UBPRE013. It is calculated as the ratio of "Net Income (RIAD4340)" to "Average Total Assets (UBPRD659)". Notice that net income does not have a particular UBPR code, and we directly use the corresponding Call report mnemonic instead.

For the margin ratio, we use "Average Earning Assets as a percent of Average Assets," for which the UBPR code is UBPRE014. It is given as the ratio of "Institution Average Earning Assets Calendar Year Basis of Calendar Quarter Average Date (UBPRD362)" to "Average Total Assets (UBPRD659)". For loan ratio, we use "Net Loss as a percent of Average Total Loans and Leases," for which the UBPR mnemonic is UBPRE019. It is given as the ratio of "Net credit losses on loans and leases (UBPR1795)" to "Average Total Loans Leases (UBPRE386)".

\subsubsection{Downloading Bulk Data}

The FFIEC website allows for bulk data download for researchers through the ffiec.gov website. Simply click on FFIEC reports and then the "Reports of Condition and Income (Call)" link. Each quarterly bulk data download contains between thirty and fifty files, with each of these files containing information about a variety of variables. These files are organized into three sections: First, a list of variables included in the file, second, the corresponding definitions of the variables included in the file, and third, a list containing each bank ID and their corresponding values regarding the specified variables. To extract the desired variables from our dataset, one can use a variety of methods. In our case, we use Java programming language to program a "sifter" that locates the files containing specific variables, then extracts each variable for each bank. We achieve this by iterating through every file in each quarterly report and searching for the specific variable name in the first section of the file. When found, we then iterate through the file to find the value of this specific variable for each bank.

We map data through a hierarchy of files. First, one can form a folder for each variable, then generate files corresponding to each bank inside these folders. Inside these files, each instance of a variable is represented by the quarterly number (the 3/31/2001 file is number 0 , while 6/30/2020 is number 77). There are a few inconsistencies in the data that we must examine. Oftentimes, banks do not report specific values, or participate in activities tracked by these values. These are represented by white "blank" space in the raw files. We account for this by simply not including them in our extracted data, hence there may be skips in the quarterly number inside the corresponding files. These skips do not change our methodology: we will continue to use regressions as per normal, except with different $x$-values (which represent the time variable of the corresponding quarter number). 
Many banks participate in mergers or begin/end tracking data within our time frame. However, because our research aims to analyze the shift, slope and volatility features of financial institutions, mergers do not affect these parameters as much as one might expect. One reason is that our variables are ratios, and they don't change much due to a merger. Many banks do not report data for some quarters or are established either after 2001 or failed before 2020. Hence, we only consider banks which contain at least 8 quarters of data before after the shock to generate a pattern. For banks that begin or fail within our time frame, we preserve this data because it is simply represented with a lack of data points during the period of the respective bank's non-existence. Given enough data points, trends within our data should still be observed irrespective of the duration of the bank's existence.

\subsubsection{A Closer Look at Capital Ratios}

Having gathered the quarterly data for financial variables at each bank, and having an organized dataset, and can begin examining trends within these variables as described in the previous section. Consider Figure 6, where you can find quarterly capital ratios for four banks all in different charts. We then go ahead and calculate shift and slope parameters for those four largest banks in the following page. Because we run a regression analysis with a time dummy variable to distinguish between before and after crisis, the slope for the two periods are the same for a given bank. Recall that Dummy variable regression analysis enables us to keep the slope of the regression lines constant and only shifts them from one period to the next period.
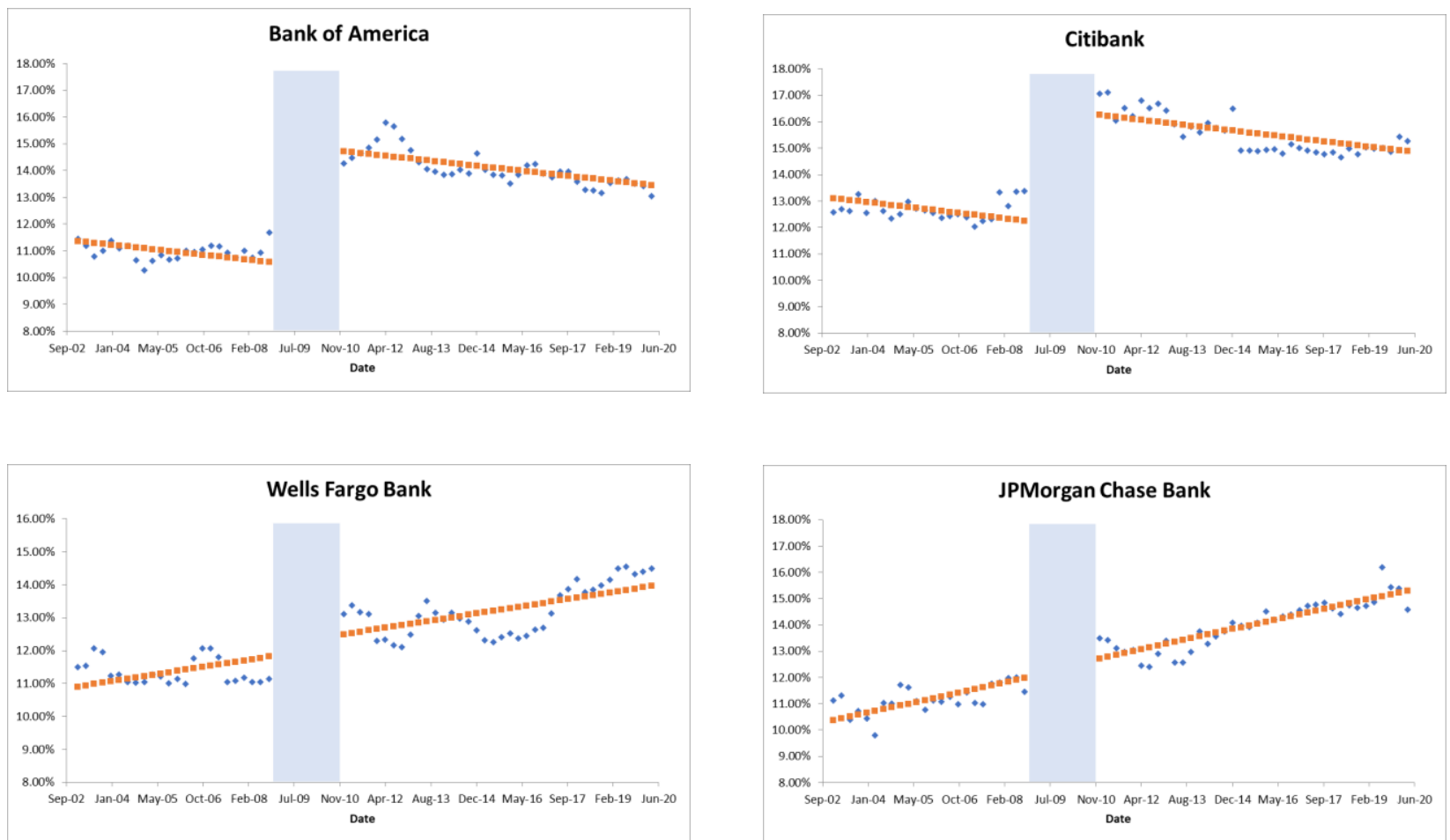

Figure 6. Regression analysis with dummy crisis variable for capital ratios at the four largest banks. Blue marks are actual data, whereas orange dotted lines are regression lines. Slope of lines before and after crisis don't change for bank i

Dummy variable is set at 0 from 2002-Q4 to 2008-Q3 and it is set to 1 from 2010-Q4 to 2020-Q2. We skip the 2-year crisis/transition period starting from 2008-Q4 all the way to 2010-Q3 as it has the potential to distort the numbers. We should make a few comments at this stage. We first note that, it is possible to do the analysis without such a transition period at all. That is, we can still implement regression analysis with dummy variable where we split the data set into two periods of before-crisis and after-crisis only. We suspect that such a breakdown will weaken the results since the transition period is very volatile. That's why we prefer to separate out the during-crisis period and do not include it in the analysis.

It is easy to observe various patterns in those charts for individual banks and that's what we would like to explore and have a deeper understanding of. Notice that we greyed out the transition/crisis period in the middle. Upon inspection it seems that our results are quite satisfactory, and the data fits the regression model very well. 
Fitted regression lines are clearly downward sloping for Bank of America and Citibank, with a big shift happening during the transition period. That is certainly not the case for JPMorgan Chase and Wells Fargo banks. It is interesting to note that Citibank and Bank of America were the largest recipients of TARP government funding during the 2007-2009 financial crisis. One would need to dig deeper beneath the surface to understand what kind of strategies or regulatory requirements might have led up to Bank of America and Citibank raising their capital ratios markedly during the crisis period. One might say that the positive shift is due to government bailout. We suspect that this might partially explain the situation and that it requires another hypothesis testing and analysis. That would be the subject of another research paper. Instead we provide the numerical values of the shift and slope parameters in Table 1 below for the same four banks.

Table 1. Shift and slope parameters for the largest four banks. Data is quarterly from 4th quarter of 2002 till end of 2nd quarter of 2020

\begin{tabular}{lcc}
\hline & Shift parameter & Slope parameter (yearly) \\
\hline Bank of America & $+4.45 \%$ & $-0.14 \%$ \\
Citibank & $+4.33 \%$ & $-0.15 \%$ \\
Wells Fargo Bank & $+0.32 \%$ & $+0.16 \%$ \\
JPMorgan Chase Bank & $+0.13 \%$ & $+0.28 \%$ \\
\hline
\end{tabular}

Shift parameter is simply calculated as the vertical distance between before and after-crisis regression lines. That number is reported in the regression analysis results as the coefficient of the dummy variable. Here is the regression results for Bank of America in Table 2:

There might be some qualitative differences between the business models for these banks with Bank of America and Citibank employing similar sets of strategies while Chase and Wells Fargo bundled together and utilizing completely different rules. Our interpretation of the situation is simple and has to do with learning and experience. Bank of America and Citibank seem to stretch the limits and hold amounts of capital close to minimum levels dictated by the federal bank regulators. As time goes by, those banks seem to forget hard learned lessons of the past. In order to increase their leverage position for increased profitability they decrease capital amounts over time. Capital ratio is now getting weaker over time. This is the case until the next crisis hits and they realize or are told by regulators to increase capital. Capital ratio abruptly increases following the crisis and yet within 10 years the ratios are back to where they were before the previous crisis.

Table 2. Regression with crisis dummy variable results for capital ratios at Bank of America (2002-2020)

\begin{tabular}{|c|c|c|c|c|c|c|c|c|}
\hline \multicolumn{2}{|c|}{ Regression Statistics } & & & & & & & \\
\hline Multiple R & 0.967025 & & & & & & & \\
\hline R Square & 0.935138 & & & & & & & \\
\hline Adjusted R Square & 0.932976 & & & & & & & \\
\hline Standard Error & 0.00416 & & & & & & & \\
\hline Observations & 63 & & & & & & & \\
\hline \multicolumn{9}{|l|}{ ANOVA } \\
\hline & $d f$ & $S S$ & $M S$ & $F$ & Signific. $F$ & & & \\
\hline Regression & 2 & 0.01497 & 0.00749 & 432.522 & $2.29 \mathrm{E}-36$ & & & \\
\hline Residual & 60 & 0.001038 & $1.7 \mathrm{E}-05$ & & & & & \\
\hline \multirow[t]{3}{*}{ Total } & 62 & 0.016008 & & & & & & \\
\hline & & Standard & & & & Upper & Lower & Upper \\
\hline & Coefficients & Error & t Stat & $P$-value & Lower $95 \%$ & $95 \%$ & $95.0 \%$ & $95.0 \%$ \\
\hline Intercept & 0.254476 & 0.02259 & 11.2643 & $1.946 \mathrm{E}-16$ & 0.209286 & 0.299 & 0.2093 & 0.2997 \\
\hline Date & $-3.7 \mathrm{E}-06$ & 5.84E-07 & -6.4137 & $2.478 \mathrm{E}-08$ & $-4.9 \mathrm{E}-06$ & $-3 \mathrm{E}-06$ & $-4.9 \mathrm{E}-06$ & $-2.6 \mathrm{E}-06$ \\
\hline Dummy & 0.044483 & 0.00237 & 18.8002 & $7.867 \mathrm{E}-27$ & 0.03975 & 0.049 & 0.0397 & 0.0492 \\
\hline
\end{tabular}


The case of Wells Fargo and JPMorgan Chase banks seem to suggest a totally different story where these banks increase their deposit base with core deposits with less than $\$ 250,000$ deposit insurance limits. These deposits are loyal and won't disappear with a crisis. As such it seems these banks have transformed themselves following the crisis. Whether these trends will be long terms is yet another story.

We next move into volatility calculations. In the following Table 3, we present one interpretation of volatility as the standard error of the sample mean of financial data. The numbers are uniform and easy to interpret across the board. Volatility has declined from its high levels before the crisis. The highest decrease as a percentage is with JPMorgan Chase bank at $-25.9 \%$ and the lowest decrease is at Wells Fargo bank at $-8.6 \%$. Regardless the figures are quite significant.

Notice that the use of standard error as a proxy for volatility does not necessarily reflect the volatility levels in absolute value, however they are great for making before- and after-crisis comparisons. The decline in volatility is telling a great many stories. We maintain that crises are characterized by high volatility periods suddenly and abruptly ending with periods of tranquility. One might give the example of a storm in the sea at night followed by serene waters in the following morning as if nothing happened in the previous night. All four of these largest US commercial banks have experienced reduction in volatility following the crisis.

Table 3. Change in standard error as proxy for volatility at the four largest US banks before and after crisis

\begin{tabular}{lccc}
\hline & $\begin{array}{c}\text { Standard error } \\
\text { (proxy for volatility) } \\
\text { before crisis }\end{array}$ & $\begin{array}{c}\text { Standard error } \\
\text { (proxy for volatility) } \\
\text { after crisis }\end{array}$ & $\begin{array}{c}\text { Change in standard } \\
\text { error }\end{array}$ \\
\hline Bank of America & $7.95 \times 10^{-6}$ & $6.82 \times 10^{-6}$ & $-14.2 \%$ \\
Citibank & $9.72 \times 10^{-6}$ & $8.45 \times 10^{-6}$ & $-13.1 \%$ \\
Wells Fargo Bank & $10.8 \times 10^{-6}$ & $9.85 \times 10^{-6}$ & $-8.6 \%$ \\
JPMorgan Chase Bank & $9.24 \times 10^{-6}$ & $6.84 \times 10^{-6}$ & $-25.9 \%$ \\
\hline
\end{tabular}

3.3 Choosing the Model

Let's assume you already implemented the steps of the discussion above and have a decent time series data of financial ratios for a certain period which covers the shock event, such as a financial crisis. That is, you used the relevant formulas and applied them to the financial data to derive a series for the financial ratios that you would like to analyze. Notice that there is quite a lot of flexibility available for the researcher to conduct the analysis. Below we provide a simple algorithm to organize the analysis into various steps.

Step 1: Split the time series financial data either into two periods as the before-crisis and after-crisis periods, or into three periods as the before-, transition, and after-crisis periods. For best results one should ensure there are enough data points (a minimum of 20 quarters would do) in each of these two periods. The researcher can omit the shock period or not depending on the length of the transition. If long, the transition period data can certainly be removed and not included in either period before or after the shock.

Step 2: One should plot charts for the given financial ratios and before the analysis of the charts can begin, should start by constructing "ad hoc" a relevant model that seem to fit the data series at hand. In our case, our focus was to understand the effects of the 2007-2008 financial crisis on each specific financial variable, i.e. the financial ratio, of interest.

Step 3: To examine the change in trend of a variable created by the crisis, we propose three different techniques. Firstly, one can run a regression with a time dummy variable that is set to equal to 1 if data extracted after the crisis, and 0 otherwise. This will only generate a shift parameter which will be further analyzed as mentioned in subsection below. Secondly, we can run two separate regressions for both periods hence generating two different slopes and shift parameters that will be further analyzed below as well. Thirdly, we would like to see if there is change in volatility for the two periods, preferably using standard errors for the dataset on each side of the shock. One can conjecture that the volatility will be somewhat higher for the pre-crisis period and somewhat higher post-crisis. A routine hypothesis test can be run across all banks to help decide whether that postulate is true or not. 


\subsubsection{Using a "Period" Dummy Variable}

If the financial ratio under analysis seem to exhibit a shift following the crisis, it would make sense to use a regression analysis with a dummy variable which will fit two straight parallel lines, one to the before-crisis data and one to the after-crisis data. We realized, for example, when we studies capital ratios in the four major U.S. banks that a shift up in those ratios was visible in the data. Whenever that's the case, and for each bank's time-series trend associated with a financial ratio, we perform a linear regression with a dummy variable that represents the relative time of the shock (before or after), as seen in Figure 7. To examine the relative shift of the variable, we create a shift parameter equal to the dummy variable divided by the value of the variable right before the shock.

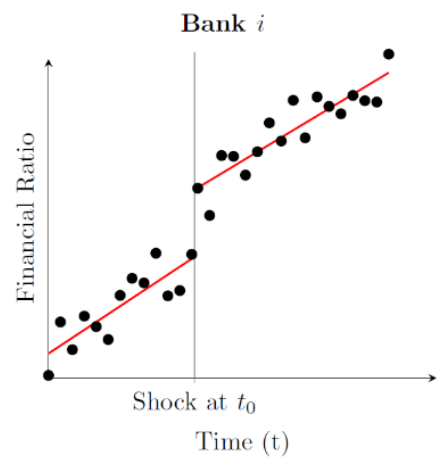

Figure 7. Extraction of shift and slope parameters from each bank i. Note that the researcher can run the regression equation once using the dummy (binary) variable "crisis"

Two analyses can then be utilized to evaluate the extent of the shock's effects. First, the shift parameters across all banks can be graphed as a histogram, which can then be analyzed for a general trend in change. The researcher, for example, can perform a hypothesis test to infer whether the change is significantly different from 0 (zero). In the case of specific financial ratios such as the capital ratio, one would be almost certain to test whether the capital ratio rise after the shock. So, the null hypothesis will be that the shift is set equal to zero, and the alternative hypothesis will be such that the shift is greater than 0 (zero). A one-sided hypothesis test like this would provide more significant result than a standard two-sided test.

Secondly, the shift parameter can be plotted against another financial variable's value right before the shock, such as total assets, to determine if a correlation exists. Each bank will correspond to a singular data point. Consider a hypothetical example where that secondary financial variable is total assets for each individual bank, and as shown in Figure 8, a simple plot and the subsequent regression analysis would determine the varying effects of the crisis across different types of banks classified in terms of size. The researcher can then run tests to see if that relationship is strong and evidence exists for any causal relationship.

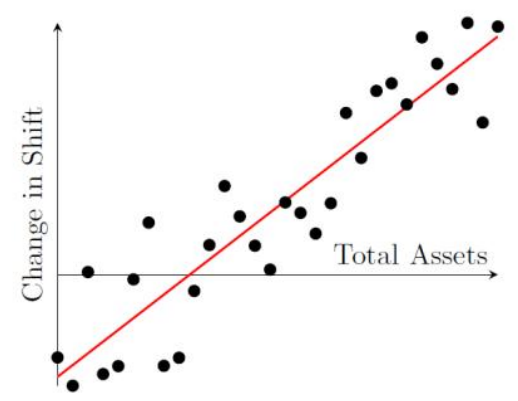

Figure 8. Shifts for varying bank sizes. A regression is run to examine the correlation between total assets before the shock and the percent change in shift.

\subsubsection{Direct Changes}

The dummy variable method, per above, is a simplified version of this second proposed method of measurement. Rather than running one linear regression with a dummy variable, we run two linear regressions, one on data before the shock and one on data after the shock. This can be useful if, upon inspecting the chart, it seems the slopes for 
before the crisis and after the crisis period don't look the same. To determine correlation between parameters before and after the shock, one can employ any of the following three methods similar to those described above. First, by plotting percent change of slope and y-intercept on two histograms. Second, creating scatter plots that compare: (i) Percent change of slope and percent change of $y$-intercept, (ii) Slope before the crisis and slope after the crisis, and (iii) $y$-intercept before the crisis and $y$-intercept after the crisis. Third, by plotting percent change of slope or $y$-intercept against the value of a financial variable before the shock, such as total assets.

We would like to elaborate on one of these suggestions above, the scatter plot for slopes. That can shed insight into how the analysis can be performed similarly for other items listed above. Suppose that the researcher generates a list of pairs representing slopes for the financial ratio for each bank, one for before- and one for after-crisis periods. The slope variables can now be plotted on a scatterplot with before-crisis value on the $x$-axis and after-crisis slope on the $y$-axis. If the expectation is that the slopes are bigger after-crisis, one would expect to see data points above the $45^{\circ}$-degree line, that is, the line with equation $y=x$. Alternatively, one can rather investigate percentage changes in the slopes and plot them against, say for example, asset size on the $x$-axis. That demonstrates size effects to the slope parameter. For example, if researcher believes that large banks are either more sensitive to shocks/crises or less so, that would be a natural thing to look at. Obviously, there are a lot of alternatives for selection of the financial variable on the $x$-axis. That shows the variety of selections available to the researcher.

\subsubsection{Volatility}

The third parameter, that is, volatility is somewhat different than shift or slope parameters. One can measure volatility in a variety of ways, and then examining changes in the volatility parameter from pre-crisis to transition, and from transition to the after-crisis period would be very useful for various reasons. Understandably, high volatility is usually associated with pre-crisis periods. It makes perfect sense to investigate volatility not only to quantify the impact of a given crisis after it is over but also to predict future crises. That is, if it is true that in general crises are preceded by high volatility in certain financial ratios, that in and of itself is quite useful for early detection systems.

For measurement purposes, one can define the volatility of a variable in a bank across a time span to be the standard error when a linear regression is applied to these data points. Hence, we can obtain two measures of volatility with our two regressions (per bank): one before the crisis, and one after the crisis. We then employ the tools used in the previous two methods to identify the effects of the crisis by simply plotting percent change of volatility on a histogram, creating a scatter plot that compares volatility before the crisis with volatility after the crisis, or measuring percent change of volatility against the value of a financial variable before the shock. Bank regulators and policymakers complain that it is hard to get trigger warnings from the financial data, which is very complicated in general. A volatility parameter, whichever way defined, can provide benefits for regulators in that regard. One should investigate previous banking crises periods and see which financial ratios seems to be more sensitive to shocks and crises.

\section{Discussion}

In this section we would like to summarize and discuss the findings in Section 3. Recall that we observed, at the beginning of section 3, certain patterns in quarterly capital ratios for the largest US banks. The most striking one being that following the 2008-09 financial crisis banks have increased their capital levels markedly, and yet those high rates are waning since 2010. That year saw a critical event in banking with the introduction of the Dodd-Frank Act. That event implemented the so-called Volcker Rule, forbidding banks to undertake certain risky investments such as proprietary trading. This event might suggest that a certain form of "forceful" learning happened among banks during and right at the end of the crisis. Yet it seems that banks have forgotten already the lesson learned and returned to business as usual.

We then moved our attention onto other financial ratios to see if similar patterns exist there too. To our surprise, patterns are different and yet it is possible to describe the trends by way of focusing on shift and slope parameters. Comparing before- and after-periods, we notice that there is always a shift followed by a trendline of similar slope to pre-crisis period. That gave us the inspiration for using a time dummy variable and checking the significance of a regression analysis with a dummy variable. The results are significant suggesting that indeed slope remains the same. So, shift is a parameter describing the size of the dislocation whereas slope is a parameter inherent to each bank and yet it is not affected by crises. One analogy here would be useful. It seems as if there is an American football game where the attacking team is in game when the team is on attack, whereas the defending squad takes over when the opponent team attacks. Bank risk management teams are in general on the side when things go smooth and yet they are back in business when there is some disturbance in the marketplace. 
The volatility parameter is somewhat different in nature from those of shift and slope. Volatility helps the researcher/practitioner define the length of the crisis period and hence is quite useful for splitting the period for which data is available into three terms: before-crisis, transition/crisis, and after-crisis periods. We used standard deviation in this paper to measure volatility in the three periods. It is possible to also use a different risk metric such as the Value-at-Risk (VaR) or Expected Shortfall to describe volatility depending on the framework at hand.

\section{Conclusion}

In this paper, we provided qualitative insight into how to analyze the impact of a financial crisis on bank financial ratios. We focused our attention on the four largest US banks, yet the framework and subsequent algorithm we proposed can easily be applied to a larger number of banks, or even the whole banking system. Since US banks span such a big range in terms of asset sizes, they seem to utilize different technologies and risk management strategies. One of the key ideas of the method that we suggest is to identify the periods as pre-crisis and post-crisis and then find a suitable regression analysis method that fits the data at hand. This approach provides a lot of flexibility for the practitioner, and consequently, there is no need to run complex time series analyses.

There is various directions one can further the findings of this paper. First, instead of looking into the largest four financial institutions one can focus attention, for example, to tier 1 banks representing the largest 25 US banks. Are there significant differences between banks in different groups? Are community banks more sensitive to crises in terms of liquidity ratio measure? Do large banks increase capital ratios more than small banks as a percentage following a crisis? How about trading assets and liabilities accounts? Do they decrease following a crisis? There is a plethora of financial ratios available for research. Secondly, standardizing the three parameters of slope, level and volatility presented in this paper can be considered in future research. Practitioners can focus attention on key financial ratios when they run the analyses and come up with their own in-house formulas that reflects to their bank's situation.

Lastly, systemic risk has become a focal point for both regulators and financial researchers. The measures developed to identify the level of systemic risk don't seem to be successful as of this date. Can our analysis be extended to help construct such a risk measure? One can argue that it would be most appropriate to calculate systemic risk with a "volatility" measure. Such measure should produce a satisfactory number that can summarize the overall riskiness of the whole banking system. There have already been some good quantitative models that have been suggested to explain how to approach this problem. For example, Acemoglu, Ozdaglar and Tahbaz-Salehi (2015) propose a financial network modeled with a mathematical graph structure where financial institutions are represented by vertices and cash flows between institutions are denoted by weighted edges. They conclude that tighter network is reduces probability of failure of an individual bank, however they also posit that overall systemic risk increases as a result of such a tight network of banks. Research in this area is growing, and to our understanding this will be a big area of focus in upcoming years.

\section{References}

Acemoglu, D., Ozdaglar, A., \& Tahbaz-Salehi, A. (2015). Systemic Risk and Stability in Financial Networks. American Economic Review, 105(2), 564-608. https://doi.org/10.1257/aer.20130456

Bernanke, B. (2018, Fall). The Real Effects of Disrupted Credit: Evidence from the Global Finan-cial Crisis. Brookings Institution Paper, pp. 251-322. https://doi.org/10.1353/eca.2018.0012

Bulut, L., \& Nal, O. (2009). Market Discipline in Turkey Before and After the 2001 Financial Crisis. Review of Middle East Economics and Finance, 5(1), 1-34. https://doi.org/10.2202/1475-3693.1183

Diamond, D., \& Dybvig, P. (1983). Bank Runs, Deposit Insurance, and Liquidity. Journal of Political Economy, 91(3), 401-419. https://doi.org/10.1086/261155

Embrechts, P., Resnick, S. I., \& Samorodnitsky, G. (1999). Extreme Value Theory as a Risk Management Tool. North American Actuarial Journal, 3(2), 30-41. https://doi.org/10.1080/10920277.1999.10595797

Freixas, X., \& Rochet, J.-C. (2008). Microeconomics of Banking (2nd ed.). Cambridge, MA: MIT Press.

Greene, W. (2017). Econometric Analysis (8th ed.). New York: Pearson. Retrieved from https://www.pearson.com/us/higher-education/program/Greene-Econometric-Analysis-8th-Edition/PGM334862 .html

Guo, Z.-Y. (2017). Heavy-tailed Distributions and Risk Management of Equity Market Tail Events. Journal of Risk \& Control, 31-41. https://doi.org/10.2139/ssrn.3013749 
Keown, A., Martin, J., \& Petty, W. (2014). Foundations of Finance (8th ed.). New Jersey: Pearson.

Litterman, R., \& Scheinkman, J. (1991). Common Factors Affecting Bond Returns. Journal of Fixed Income, 1(1), 54-61. https://doi.org/10.3905/jfi.1991.692347

Maniam, B., \& Nal, O. (2012). Bailing Out Too Big to Fail Banks. Journal of International Finance Studies, 12(4), $1-21$.

The Financial Crisis Inquiry Commission (of the US Congress). (2011). The Financial Crisis Inquiry Report: Final Report of the National Commission on the Causes of the Financial and Economic Crisis in the United States. Washington, DC: U.S. Government Printing Office. Retrieved from https://www.govinfo.gov/content/pkg/GPO-FCIC/pdf/GPO-FCIC.pdf

\section{Copyrights}

Copyright for this article is retained by the author(s), with first publication rights granted to the journal.

This is an open-access article distributed under the terms and conditions of the Creative Commons Attribution license (http://creativecommons.org/licenses/by/4.0/). 